\title{
An Atlas of Oblique-Incidence Ionograms (A Digest) ${ }^{1}$
}

\author{
Vaughn Agy, Kenneth Davies, and Roger Salaman
}

(June 24, 1960)

\begin{abstract}
A brief description Tis given of an atlas (published separately) of oblique-incidence ionograms obtained on two paths, 1,150 and 2,370 kilometers.
\end{abstract}

The purpose of this note is to describe an atlas of oblique-incidence ionograms recently compiled by the authors [1]. ${ }^{2}$ The atlas is intended to serve a twofold purpose: First, to provide a reasonably comprehensive introduction to this type of ionogram for those workers who are not now familiar with them, and second, to present records which illustrate the various propagation characteristics of the specific paths used by the National Bureau of Standards. An analytical study of the technique and the experimental results was given by Agy and Davies [2]. To date, NBS sweep-frequency experiments have been carried out over two approximately east-west paths [2]: Washington, D.C.-St. Louis, Mo. (about $1,150 \mathrm{~km}$ ) [3, 4], and Washington, D.C.-Boulder, Colo. (about 2,370 km) [5]. A vertical incidence ionosonde was operated at the path midpoint in each case.

The atlas is divided into four parts, namely: 1. Introduction; 2. Washington-St. Louis routine records; 3. Washington-Boulder routine records; and 4. Washington-Boulder experimental records.

The introduction contains a discussion of the equipment together with charts necessary for the identification of certain modes of propagation and a brief description of the records.

The next two sections illustrate diurnal and seasonal variations, layer formation and disappearance,

\footnotetext{
${ }_{1}^{1}$ Contribution from Central Radio Propagation Laboratory, National Bureau

2 of Standards, Boulder, Colo.
2 Figures in brackets indicate the literature references at the end of this paper.
}

spread echo, MUF extension and several other phenomena of interest. The magnetic $K$ figures are included to provide a basis for judging the effect of magnetic disturbance. The accompanying figure is a sample page from the section dealing with the Washington-Boulder path.

The final section is devoted to various short term experiments over the Washington-Boulder path. Expanded time-delay and frequency scales were used as well as shorter pulse durations than in the previous cases. Equipment effects such as pulse width and receiver gain are considered. Detailed sequences of oblique ionograms during magnetic storms are shown together with the midpoint vertical-incidence ionograms. A sequence of $A$-scan records is presented which shows how the field strength varied near the MUF during one sweep.

\section{References}

[1] V. Agy, K. Davies, and R. Salaman, An atlas of obliqueincidence ionograms, NBS Technical Note No. 31 (1959). Distributed by United States Department of Commerce, Office of Technical Services, Washington 25, D.C. Price $\$ 2.25$.

[2] V. Agy and K. Davies, Ionospheric investigations using the sweep-frequency pulse technique at oblique-incidence, J. Research NBS 63D, 151 (1959).

[3] P. G. Sulzer and E. E. Ferguson, Sweep-frequency obliqueincidence ionospheric measurements over an $1,150 \mathrm{~km}$ path, Proc. IRE 40, 1124 (1952).

[4] B. Wieder, Some results of a sweep-frequency propagation experiment over an 1,150 km east-west path, J. Geophys. Research 60, 395 (1955).

[5] P. G. Sulzer, Sweep-frequency pulse-transmission measurements over a $2,400 \mathrm{~km}$ path, J. Geophys. Research 60. 411 (1955). 

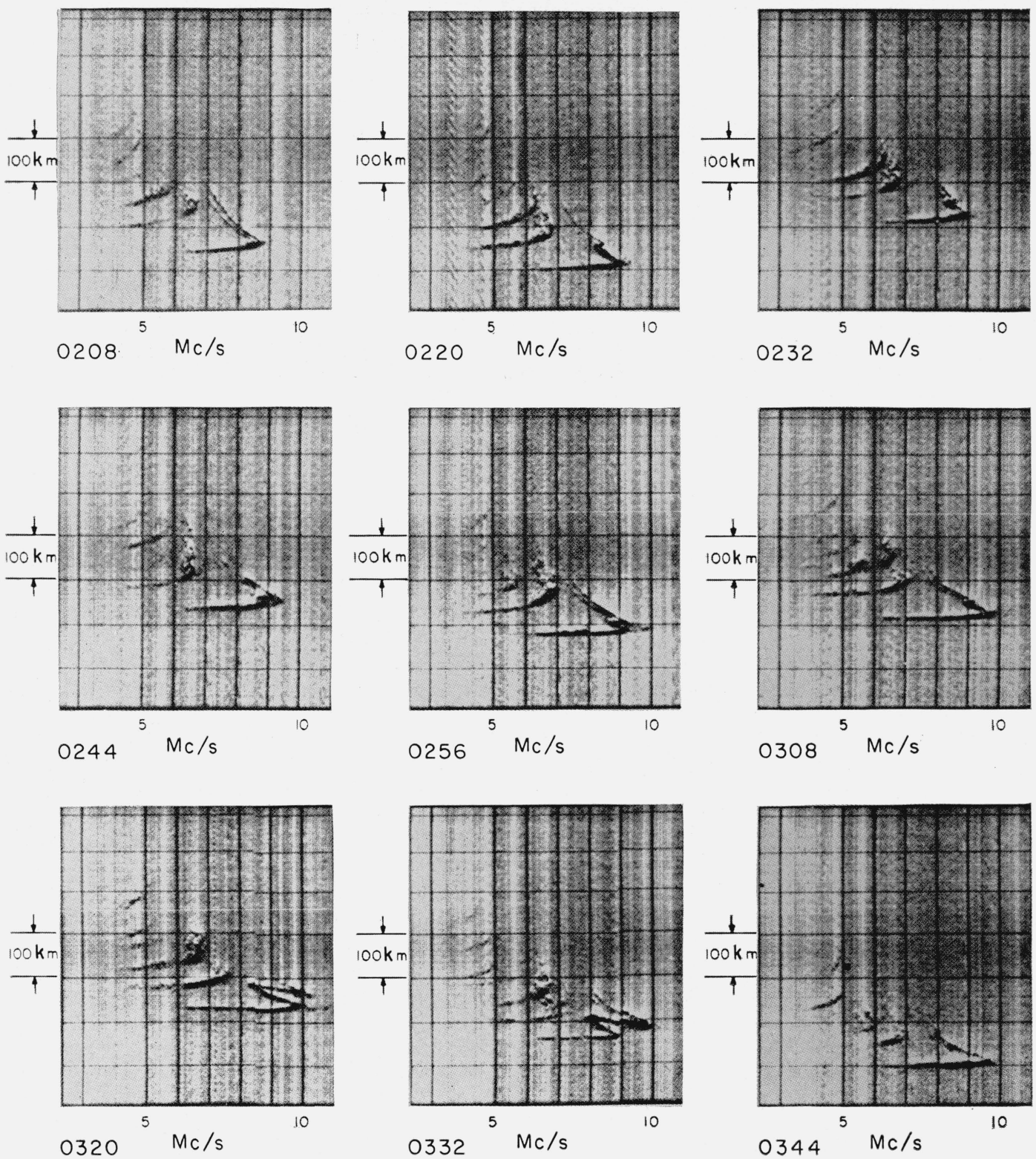

Sample page from the Atlas showing development of stratification possibly produced by off-path reflections.

Washington-Boulder path, November 5, 1953.

(Paper 65D1-100) 